\title{
Konstruksi Kalimat pada Dialog Film Rumah Tanpa Jendela Karya Aditya Gumay
}

\author{
Ni Made Sri Maharani*, Made Sri Satyawati, I G.N.K. Putrayasa \\ Prodi Sastra Indonesia, Fakultas Ilmu Budaya, Unud \\ [srimertha8@gmail.com], [srisatyawati@gmail.com], [ign_kt_putrayasa@unud.ac.id] \\ Badung, Bali, Indonesia \\ *Corresponding Author
}

\begin{abstract}
The study entitled "Konstruksi Kalimat Pada Film Dialogue Rumah Tanpa Jendela karya Aditya Gumay". The purpose of this study is to describe the structure, type, and meaning of the sentence in Film Dialogue Rumah Tanpa Jendela. The theoretical basic used in this study is structural theoryaccording to Verhaar (2012) and is supported by operational approaches in semantic cognitive, connotative, and emotive meaning. The method and technique used to collect data in this study is the method refer to thenote taking technique. At the stage of presenting the results of data analysis, the method used is ushed. At the stage of presenting the results of data analysis informal and formal methods are used.The results of this study are foundin the structure of single sentences and compound sentences divided into two sentence patterns, namely single sentence patterns and compound sentence patterns. Single sentence pattern consist of SPO type, SPKet type, SPOKet type, SPPel type, PO type, POKet type, SP type, PS type, Pket type, and PSKet type. Compound sentence patterns consist SPKe+Pket type, SP+SPKet type, SPKet+SP type, SP+SketPO type, PKet+SPKet type, SPKet+Pket type, Konj+SP+SPO, and $\mathrm{SP}+\mathrm{SP}$ type. Type of sentence based onthe nuber of clauses based on syntatic form, basedon the internal struture ofthe main clause, based on the presence or absence of changes in exclusion, based on syntactic functions.
\end{abstract}

Keywords : sentence structure, sentence type, cognitive, connotative, and emotive meanings

\begin{abstract}
Abstrak
Penelitian ini berjudul "Konstruksi Kalimat pada Dialog Film Rumah Tanpa Jendela karya Aditya Gumay". Tujuan penelitian ini untuk mendeskripsikan struktur, jenis,dan makna kalimat yang terdapat pada dialog film Rumah Tanpa Jendela. Landasan teori yang digunakan dalam penelitian ini adalah teori struktural menurut Verhaar (2012) dan didukung oleh pendekatan operasional dalam makna semantik kognitif, konotatif, dan emotif. Metode dan teknik yang digunakan untuk mengumpulkan data dalam penelitian ini adalah metode simak dengan teknik catat. Pada tahap analisis data digunakan metode agih. Pada tahap penyajian hasil analisis data digunakan metode informal dan formal.Hasil penelitian ini adalah ditemukan struktur kalimat tunggal dan kalimat majemuk terbagi atas dua pola kalimat, yaitu pola kalimat tunggal dan pola kalimat majemuk. Pola kalimat tunggal terdiri atas tipe SPO, tipe SPKet, tipe SPOKet, tipe SPPel, tipe PO, tipe POKet, tipe SP, tipe
\end{abstract}


PS, tipe Pket, dan tipe PSKet. Pola kalimat majemuk terdiri atas tipe SPKet+PKet, tipe SP+SPKet, tipe SPKet+SP, tipe SP+SKetPO, tipe PKet+SPKet, tipe SPKet+Pket, tipe konj+SP+SPO, dan tipe $\mathrm{SP}+\mathrm{SP}$. Jenis kalimat berdasarkan jumlah klausa, berdasarkan bentuk sintaksis, berdasarkan struktur internal klausa utama, berdasarkan ada tidaknya perubahan dalam pengucapan, berdasarkan fungsi sintaksis.

\section{Kata kunci: struktur kalimat, jenis kalimat, makna kognitif, konotatif, dan} emotif

\section{Latar Belakang}

Chaer (2007:1) menyatakan bahasa adalah fenomena yang menghubungkan dunia makna dengan dunia bunyi, sebagai penghubung di antara kedua dunia itu, bahasa dibangun oleh tiga buah komponen, yaitu komponen leksikon, komponen gramatika, dan komponen fonologi. Jika bahasa itu merupakan satu sistem, sistem bahasa itu memiliki tiga buah subsistem, yaitu subsistem leksikon, subsistem gramatika, dan subsistem fonologi. Ketiga subsistem itu terikat pula dengan dunia pragmatik atau dunia konteks.

Film merupakan refleksi budaya bangsa. Film ingin menampilkan aspek-aspek kehidupan manusia yang dikemas dalam bahasa yang menarik dan mudah dipahami penontonnya. Dalam bahasabahasa yang digunakan tentunya terdapat pilihan kata yang disesuaikan dengan kondisi remaja saat itu yang disusun dalam konstruksi kalimat yang mudah dipahami. Kalimat-kalimat yang mendukung skenario sebuah film, jika ditonton sangat menarik untuk diamati sehingga diketahui tujuan-tujuan konstruksi kalimatnya

Penelitian yang mengkaji kalimat yang ada di dalam percakapan dialog sebuah film belum banyak dilakukan. Umumnya, penelitian-penelitian yang mengkaji sintaksis menggunakan novel sebagai objek penelitian. Melalui penelitian ini, sudah dikaji dari segi bentuk. Selain itu, dalam penelitian ini dikaji makna atau unsur semantik yang terkandung dalam kalimat-kalimat pada dialog, seperti makna kognitif, konotatif, maupun emotif.

\section{Pokok Permasalahan}

Berdasarkan latar belakang di atas, dapat dirumuskan permasalahan sebagai berikut.

a) Bagaimanakah struktur kalimat yang digunakan pada dialog film Rumah Tanpa Jendela dilihat dari fungsi, kategori, dan peransintaksis? b) Jenis kalimat apa sajakah yang digunakan pada dialog film Rumah Tanpa Jendela? c) Jenis makna semantik kognitif, konotatif, dan emotif apa sajakah yang terkandung pada dialog Film Rumah Tanpa Jendela?

\section{Tujuan Penelitian}

Adapun tujuan dari penelitian ini, sebagai berikut.

a. Untuk mendeskripsikan struktur kalimat berdasarkan fungsi, kategori, dan peran sintaksis yang digunakan pada dialog filmRumahTanpaJendela.

b. Untukmendeskripsikan jenisjeniskalimat ditinjau dari sudut (a) jumlah klausa, (b) bentuk sintaksis, (c) struktur internal klausa, (d) ada tidaknya perubahan dalam pengucapan, dan (e) fungsi sintaksis yang terdapat pada dialog filmRumahTanpaJendela.

c. Untuk mengetahui makna semantik kognitif, konotatif, dan emotif yang 
terkandung pada dialog film Rumah Tanpa Jendela.

\section{Metode Penelitian}

Metodeyang digunakan untuk mengumpulkan data penelitian ini adalah metode simak (observasi). Metode yang digunakan dalam teknik analisis data adalah metode agih. Metode agih adalah metode analisis data yang alat penentunya justru bagian dari bahasa itu. Metode penyajian hasil analisis data yang digunakan adalah metode formal dan informal. Metode informal adalah rumusan hasil analisis data dengan menggunakan kata-kata biasa, terdapat pada analisis fungsi kategori, peran,dan jenis kalimat. Selanjutnya, metode formal, yakni perumusan hasil analisis data dengan menggunakan tanda-tanda atau lambang (Sudaryanto, 1993:145).

\section{Hasil dan Pembahasan}

\subsection{Sintaksis}

Crystal (1980:346) mendefinisikan sintaksis sebagai telaah tentang kaidahkaidah yang mengatur cara kata-kata dikombinasikan untuk membentuk kalimat dalam suatu bahasa. Dalam pemakaian ini, sintaksis dikontraskan dengan morfologi, yaitu telaah tentang struktur kata. Roberts (1964:1) mendefinisikan sintaksis sebagai bidang tata bahasa yang menelaah hubungan kata-kata dalam kalimat, cara-cara menyususun kata-kata itu PSKet ini terdiri atas predikat, subjek, dan keterangan di dalamnya. Contoh tipe kalimat PSKet yang terdapat pada dialog film Rumah Tanpa Jendela adalah sebagai berikut

"Mungkin P mereka S ke rumah Alya" Ket

\subsection{Struktur Kalimat}

\section{a) Tipe SPO}

Tipe SPO termasuk dalam kalimat tunggal. Tipe SPO ini terdiri atas subjek, predikat, dan objek di dalamnya. Contoh tipe alimat SPO yang terdapat pada ldialog film Rumah Tanpa Jendela adalah sebagai berikut.

\section{1). "Dava ingin punya jendela?"}

\section{b) Tipe SPKet}

Tipe SPKet merupakan termasuk dalam kalimat tunggal. Tipe SPKet ini terdiri atas subjek predikat, dan keterangan di dalamnya. Contoh tipe kalimat SPKet yng terdapat pada dialog film Rumah Tanpa Jendela adalah sebagai berikut

"Aldo sudah ketemu sama nenek?"

\section{c) Tipe SPOKet}

Tipe SPOKet merupakan termasuk dalam kalimat tunggal. Tipe SPOKet ini terdiri dari subjek, predikat, objek, dan keterangan di dalamnya. Contoh tipe kalimat SPOKet yang terdapat pada dialog film Rumah Tanpa Jendela adalah sebagai berikut

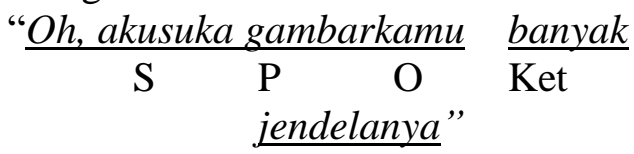

\section{d) Tipe PS}

Tipe PS termasuk dalam kalimat tunggal. Tipe PS ini terdiri dari predikat dan subjek di dalamnya. Contoh tipe kalimat PS yang terdapat pada dialog film Rumah Tanpa Jendela adalah sebagai berikut

$\frac{\text { "Maafkanbunda nak" }}{\text { P S }}$

\section{e) Tipe PKet}

Tipe PKet termasuk ke dalam kalimat tunggal. PKet terdiri dari predikat dan keterangan. Contoh tipe kalimat PKet yang terdapat pada dialog film Rumah Tanpa Jendela adalah sebagai berikut.

$\frac{\text { "Ya, jawab }}{\mathrm{P}} \frac{\text { mau lah }}{\text { Ket }}$




\section{f). Tipe PSKet}

Tipe PSKet merupakan termasuk dalam kalimat tunggal. Tipe PSKet ini terdiri atas predikat, subjek, dan keterangan di dalamnya. Contoh tipe kalimat PSKet yang terdapat pada dialog film Rumah Tanpa Jendelaadalah sebagai berikut.

"MungkinPmerekaSke rumah bu Alya” Ket

\section{Pola Kalimat Majemuk}

1. Tipe SP+PKet

"Jendelanya tak ambil ikan saya ya?"

tapi, tuker sama dagangan

\section{Tipe SP+SPKet}

"Pak Sahri begitu baik hati mengizinkan aku dan si mbok tinggal

di sini"

\section{Tipe SPKet+SP}

"Kami sudah berusaha semaksimal mungkin, tapi keadaan mereka masih kritis"

\section{Tipe SP+SKetPO}

"Aku enggak bisa membayangkan, jika si mbok pada akhirnya harus pergi meninggalkanku”.

\section{Tipe PKet+SPKet}

"Kan udah jelas sekarang, kalau $\underline{a k u}$ punya adik kayagitu"

\section{Tipe SPKet+PKet}

"Ratna kita itu harus menunggu 24 jam $\underline{\text { dulu, baru }} \underline{\text { lapor }} \underline{\text { ke polisi }}$

\section{Tipe Konj+SP+SPO}

"Kalau saya sekolah ; saya bisa naik sepeda"

\section{Tipe SP+SP}

"Kami berbeda karena kami kembar tidak identik"

\subsection{Jenis - Jenis Kalimat}

5.3.1 Jenis Kalimat Berdasarkan

\section{Jumlah Klausa}

a. Tunggal Berpredikat Kalimat

\section{Nominal}

Dalam bahasa Indonesia ada jenis kalimat yang predikatnya terdiri atas nomina (termasuk pronomina) atau frasa nominal. Dengan demikian, keadaan nomina atau frasa nominal yang dijejerkan dapat membentuk kalimat asalkan syarat untuk subjek dan predikatnya terpenuhi (Putrayasa, 2009 : 83)

\section{"Rara kamu kenapa?"}

\section{b. Kalimat Tunggal Berpredikat Verbal}

Kalimat berpredikat verbal adalah kalimat yang predikatnya berupa verbal atau frasa verbal. Kalimat tunggal berpredikat verbal pada dialog film Rumah Tanpa Jendela adalah sebagai berikut.

"Eh Ratna, besok jangan lupa loh dateng"

\section{c. Kalimat Tunggal Berpredikat Adjektival}

Kalimat berpredikat adjektival adalah kalimat yang predikatnya berupa adjektiva atau frasa adjektival. Kalimat tunggal berpredikat adjektival pada dialog film Rumah Tanpa Jendela adalah sebagai berikut.

"Donald Tram itu orang terkaya di Amerika"

\section{d. Kalimat Tunggal Berpredikat Frasa Preposisional}

Kalimat berpredikat frasa preposisional adalah kalimat yang predikatnya berupa frasa preposisional (kata depan/kata penghubung), seperti ke, $d i$, pada, ini, itu, untuk, dan lain- lain. Kalimat tunggal berpredikat frasa preposisional pada dialog film Rumah Tanpa Jendela adalah sebagai berikut.

"Keluarga yang lain pada sibuk" 


\section{e. Kalimat Majemuk Setara}

Kalimat majemuk setara ditandai oleh tanda penghubung, seperti dan, atau, lalu, kemudian, tetapi, melainkan, dan sedangkan. Kalimat majemuk setara yang terdapat pada dialog film Rumah Tanpa Jendela adalah sebagai berikut.

"Iya bu, biar rumah saya gak bauk sampah, tapi bauk kambing"

\section{f. Kalimat Majemuk Bertingkat}

Kalimat majemuk bertingkat adalah kalimat yang hubungan pola-polanya tidak sederajat. Salah satu pada bagian yang lebih tinggi kedudukannya disebut induk kalimat, sedangkan bagian yang lebih rendah kedudukanya disebut anak kalimat.. Kalimat majemuk bertingkat pada dialog film Rumah Tanpa Jendela adalah sebagai berikut.

"Sekarang gini, kalau sampai mereka dateng, suruh di belakang panggung"

\subsubsection{Jenis Kalimat Berdasarkan Bentuk Sintaksis}

\section{a) Kalimat Deklaratif}

Kalimat deklaratif yang terdapat pada dialog film Rumah Tanpa Jendela adalah sebagai berikut..

\section{"Anak-anak hari ini kita belajar} mengarang ya"

\section{b) Kalimat Imperatif}

Kalimat imperatif (kalimat perintah dan kalimat larangan) yang terdapat pada dialog film Rumah Tanpa Jendela dipaparkan sebagai berikut.

\section{b.1 Kalimat Perintah}

Kalimat perintah yang terdapat pada dialog film Rumah Tanpa Jendela adalah sebagai berikut.

"Siti! Bantuin Mas Tarjo dong!"

\section{b.2 Kalimat Larangan}

Kalimat larangan mengharapkan jawaban tidak melakukan sesuatu yang disebutkan dalam kalimat itu. Oleh karena itu, Kalimat larangan yang terdapat pada dialog film Rumah Tanpa Jendela adalah sebagai berikut.

"Sebaiknya kita enggak usah deket lebih jauh lagi deh!"

\section{c. Kalimat Interogatif}

Kalimat interogatif adalah kalimat yang mengharapkan jawaban secara verbal. Jawaban ini dapat berupa pengakuan, keterangan, alasan, atau pendapatdari pihak pendengar atau pembaca. (Chaer, 2009: 189). Kalimat interogatif yang terdapat pada dialog film Rumah Tanpa Jendela adalah sebagai berikut.

\section{"Dava ingin punya jendela?"}

\section{d. Kalimat Interjektif}

Kalimat interjektif adalah kalimat yang menuatakan emosi, seperti karena kagum, kaget, terkejut, takjub, heran, marah, sedih, gemas, kecewa, tidak suka, dan sebagainya. Contoh kalimat interjektif yang terdapat pada dialog film Rumah Tanpa Jendela adalah sebagai berikut.

"Sudah berapa kali aku bilang!

\subsubsection{Jenis Kalimat Berdasarkan Struktur Internal Klausa Utama}

\section{a. Kalimat Lengkap}

Kalimat lengkap adalah kalimat yang mengandung klausa lengkap. Kalimat lengkap yang terdapat pada dialog film Rumah Tanpa Jendela.

"Aldo sudah ketemu sama nenek?"

\section{b. Kalimat Taklengkap}

Kalimat taklengkap atau kalimat taksempurna adalah kalimat yang dasarnya terdiri atas sebuahklausa terikat, atau sama sekali tidak mengandung struktur klausa (Cook, 1971). Kalimat tak lengkap yang terdapat pada dialog film Rumah Tanpa Jendela. 
"Kenapa emang?" (Kamar Andini, 00 : $12: 20-00: 12: 54)$.

\subsubsection{Jenis Kalimat Berdasarkan Ada Tidaknya Perubahan dalam Pengucapan}

\section{Kalimat Langsung}

Kalimat langsung merupakan kalimat yang langsung diucapkan oleh si pembicara. Kalimat langsung pada dialog film Rumah Tanpa Jendela adalah sebagai berikut.

"Rara nanti pulangnya jangan kemaleman ya"

\section{Kalimat Taklangsung}

Kalimat taklangsung adalah kalimat yang sudah mengalami perubahan pengucapan dari pembicara aslinya. Kalimat taklangsung pada dialog film Rumah Tanpa Jendela adalah sebagai berikut.

a. "Kata abang, cincin Ratna ada di laci kamar"

\subsubsection{Jenis Kalimat Berdasarkan Fungsi Sintaksis}

\section{a. Kalimat Biasa}

Kalimat biasa adalah kalimat yang tersusun sesuai dengan pola dasar kalimat bahasa Indonesia, yaitu S-P-(O)(Pel)-(K) atau S mendahului P. Contoh kalimat biasa yang terdapat pada dialog film Rumah Tanpa Jendela adalah sebagai berikut.

"Kalian tau enggak rumahnya dimana?"

\section{b. Kalimat Inversi}

Kalimat inversi adalah kalimat yang mengharuskan predikat mendahului subjek (berpola P-S). Kalimat inversi yang terdapat pada dialog film Rumah Tanpa Jendela adalah sebagai berikut.

"MaafkanP bunda nakS" (Sanggar Lukis, $01: 31: 37-01: 32: 56$ )

\subsection{Makna Kognitif, Konotatif, dan Emotif}

\section{Makna Kognitif}

"iya yah, ini sudah sama nenek"

Kata sudah (adverbia) pada

kalimat (1) bermakna kognitif

\section{Makna Konotatif}

"Alah, rumah samping kampung ini aja pingin naik sepeda"

Kata samping (adverbia) pada kalimat (2) bermakna konotatif

\section{Makna Emotif}

"Memangnya aku selebritis kau pikir"

Kata selebitis (pronomina) pada kalimat (3) adalah berkmakna emotif karena pernyataan kaget dan senang.

\section{Simpulan}

a) Struktur kalimat yang ditemukan dan dianalisis pada dialog film Rumah Tanpa Jendela adalah diambil dari struktur kalimat tunggal dan kalimat majemuk terbagi atas dua pola kalimat, yaitu pola kalimat tunggal dan pola kalimat majemuk. Pola kalimat tunggal terdiri atas tipe SPO, tipe SPKet, tipe SPOKet, tipe SPPel, tipe PO, tipe POKet, tipe SP, tipe PS, tipe Pket, dan tipe PSKet. Pola kalimat majemuk terdiri tipe $\mathrm{SP}+\mathrm{PKet}$, tipe $\mathrm{SP}+\mathrm{PKet}$, tipe SPKet+SP, tipe $\mathrm{SP}+\mathrm{SKetPO}$, tipe PKet+SPKet, tipe SPKet+Pket, tipe Konj+SP+SPO, dan tipe $\mathrm{SP}+\mathrm{SP}$.

b) Dalam dialog film Rumah Tanpa Jendela ditemukan jenis kalimat yang bervariasi, jenis kalimat berdasarkan jumlah klausa, berdasarkan bentuk sintaksis, berdasarkan struktur internal klausa utama, berdasarkan ada tidaknya perubahan dalam pengucapan, berdasarkan fungsi sintaksis. Makna kalimat dianalisis dari makna / unsur semantik, makna semantik yang dianalisis dibagi 
menjadi tiga, yaitu, makna kognitif, makna konotatif, dan makna emotif.

c) Makna kalimat dianalisis dari makna / unsur semantik, makna semantik yang dianalisis dibagi menjadi tiga, yaitu, makna kognitif, makna konotatif, dan makna emotif. Makna kognitif termasuk ke dalam kalimat deklaratif (pernyataan), makna konotatif. Makna konotatif termasuk ke dalam kalimat imperatif, kalimat imperatif yang mendekati kalimat larangan yang menghina dan merendahkan, yaitu Alah, rumah samping kampung ini aja pingin naik sepeda". Makna emotif termasuk ke dalam tiga jenis kalimat, yaitu kalimat interogatif, kalimat interjektif, dan kalimat deklaratif. Makna emotif yang termasuk ke dalam kalimat interogatif, yaitu "Memangnya aku selebritis kau pikir". Makna emotif yang termasuk ke dalam kalimat interjektif, yaitu "Ooo, bagus gambar kamu loh". Makna emotif yang termasuk ke dalam kalimat deklaratif, yaitu "Bikin jendelanya kaya gini aja".

\section{Saran}

Saran bagi pembaca, penelitian analisis pada dialog filmRumah Tanpa Jendela perlu diperhatikan bawa setiap dialog film mempunyai pilihan kalimat yang berbeda - beda. Pilihan kalimat disesuaikan dengan skenario yang ada dan ditampilkan, terganturng juga pada setiap situasi dan adegan di film tersebut.

\section{Daftar Pustaka}

Cahyani, Intan I Gusti Ayu (2018) "Konstruksi Kalimat padaTeks Iklan Oriflame". Skripsi (S1) Universitas Udayana, Denpasar.

Caturini, Kartika. 2015 "Pesan Ahklak dalam Film Rumah Tanpa Jendela". Skripsi (S1) Universitas
Islam Negeri Sunan Kalijaga, Yogyakarta

Chaer, Abdul. 2008. Sintaksis BahasaIndonesia:Pendekatan

Proses. Jakarta: PT Rineka Cipta.

Chaer, Abdul dan Liliana Muliastuti. Modul 1 : Makna dan Semantik.

Darmawan, Rahmat. 2011 "Analisis Diksi dan Konstruksi Kalimat dalam Terjemahan Syair Ta'lim alMuta'allim". Skripsi

Universitas Islam Negeri Syarif Hidayatullah, Jakarta.

Khairah, Miftahul dan Ridwan Sakura. 2014. SINTAKSIS (Memahami Satuan Kalimat dan Perspektif Fungsi). Jakarta. Bumi Aksara

Moeliono, dan Soenjono, Dardjowidjo. 1988. Tata Bahasa Baku BAHASA INDONESIA.

Departemen

Pendidikan dan Kebudayaan:Perum Balai Pustaka.

Muis, Ba'dulu Abdul dan H, Herman. 2004. Morfosintaksis. Jakarta: PT Rineka Cipta. 